\title{
Long-term mandibular adaptations to protrusive function: An experimental study in Macaca mulatta
}

\author{
James A. McNamara, Jr., D.D.S., Ph.D.," and F. Allen Bryan, D.D.S., M.S.** \\ Ann Arbor, Mich. \\ Twenty-three male juvenile rhesus monkeys ((Macaca mulatta) were used in an experimental study \\ of long-term mandibular adaptations to induced protrusive function. Serial protrusive appliances \\ were placed in 11 experimental animals and mandibular adaptations were monitored cephalometrically. \\ Twelve animals were used as controls. After 48 weeks significant increases in increments of \\ condylar growth and in overall mandibular length were noted in the treated animals. At the end of \\ the 144-week experimental period, the mandibles of the treated animals were 5 to $6 \mathrm{~mm}$ longer than \\ those of the control animals. The results of this study do not support the hypothesis that the \\ mandible has a genetically predetermined length. (AM J ORTHOD DENTOFAC ORTHOP 1987;92:98-108.)
}

$A_{\text {s the popularity of functional appliances }}$ as a mode of orthodontic treatment in growing persons increases, both basic biologists and clinicians ask: Can the mandible be stimulated to grow longer than it would have without treatment? At the end of the growth period, is the treated mandible longer than it would have been without clinical or experimental intervention?

The effects of altered function on the growing craniofacial complex have been studied extensively in the laboratory. Various types of appliances have been constructed that prompt the lower jaw into a protrusive position and the resulting craniofacial adaptations have been studied cephalometrically or histologically in nonhuman primates by a number of investigators. Breitner, ${ }^{1-3}$ Häupl and Psansky, ${ }^{4}$ Baume and Derichsweiller, ${ }^{5}$ and Stöckli and Willert ${ }^{6}$ have shown that the condylar cartilage exhibits compensatory tissue response to experimental alterations of the postural position of the mandible. In histochemical studies, Vogel and Pignanelli ${ }^{7}$ have found that experimental protrusion of the mandible in rhesus monkeys also results in an increase in chondrogenic activity at the head of the mandibular condyle.

Similar types of studies have been carried out in rats by Petrovic, Stutzmann, and associates. ${ }^{8-12}$ The results of these studies indicate that anterior displacement of the mandibular condyle in rats increases the growth of the condylar cartilage. A more recent study by

\footnotetext{
This research was supported in part by USPHS Grant DE-03610.

* Professor of Dentistry (Orthodontics), Professor of Anatomy \& Cell Biology, and Research Scientist, Center for Human Growth and Development, The University of Michigan.

**Departments of Orthodontics and Anatomy \& Cell Biology, The University of Michigan.
}

Petrovic ${ }^{13}$ indicates that mandibular growth augmentation can be achieved in rats when appliances simulating those used in clinical treatment of humans (for example, Bionator, Fränkel appliance) are used.

To study functional adaptation to changes in mandibular postural position in the rhesus monkey, we have used many experimental designs, the one most frequently used being the experimental design for studying functional protrusion. ${ }^{14-17}$

One unique aspect of our studies is that both functional and structural adaptations were studied in the animals simultaneously. For example, an increase in lateral pterygoid activity associated with the forward positioning of the lower jaw was noted. This new functional pattern first appeared in association with such phasic activities as swallowing and then during such tonic functions as maintenance of mandibular postural position. However, as the experiment progressed, there was a gradual return toward the preappliance levels of muscle activity. This gradual change in the level of muscle activity was correlated in time with the skeletal and dental adaptations observed in these same animals. ${ }^{14}$

The results of our studies, as well as those of others, seem to indicate that the growth of the temporomandibular joint in young persons is adaptive in nature and that the condylar cartilage is responsive to changes in function. However, the question of whether or not these mandibular adaptations are transient or permanent remains unanswered.

The only experimental studies to address this question are those of the Strasbourg group. Petrovic and coworkers ${ }^{18}$ performed an experiment using the postural hyperpropulsor on young male rats. The growth rate of 


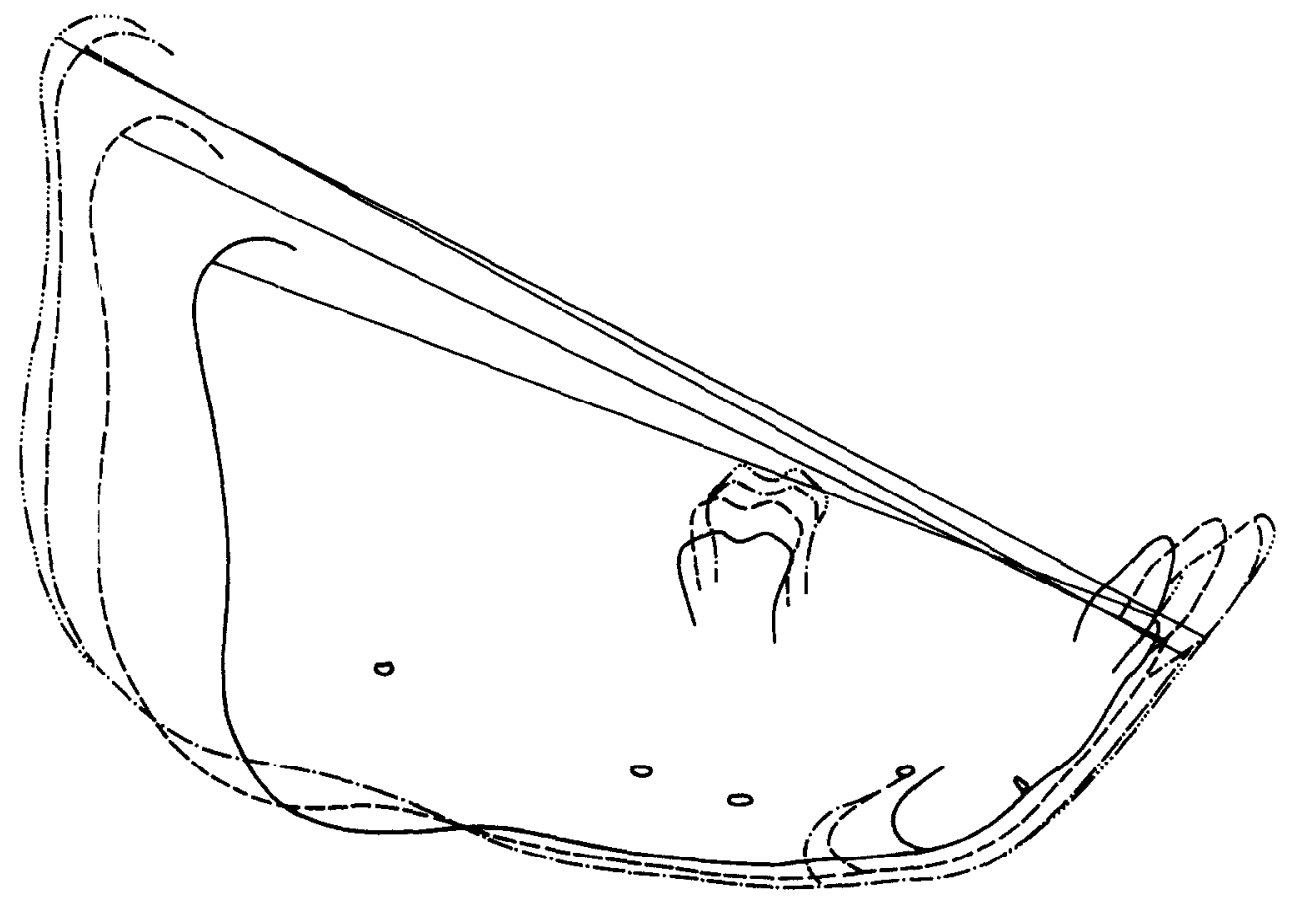

Fig. 1. Method to determine mandibular length by directly measuring the distance from infradentale anteriorly to the most posterosuperior aspect of the mandibular condyle (condylion). Superimposition of serial tracings is on the mandibular implants.

the condylar cartilage was evaluated by counting the total number of cells that had incorporated tritiated thymidine, which was injected 1 hour before an animal was killed. The amount of growth of the mandible was evaluated by measuring the distance between the posterior border of the condyle and the mental foramen on enlarged photographs and radiographs. In rats that wore the postural hyperpropulsor until the end of their growth period, the overall length of the mandible was greater than that of the controls. In addition, when the hyperpropulsor was removed, no relapse occurred.

In a more recent study, ${ }^{13}$ similar findings were reported. A simulated Bionator appliance produced a statistically significant $4 \%$ to $8 \%$ increase in overall mandibular length, depending upon the amount of bite advancement. Similar findings were reported for the postural hyperpropulsor ( $5 \%$ to $8 \%$ ). However, the greatest amount of overall increase in mandibular length was reported when either Class II intraoral elastics or a simulated Fränkel appliance was worn (14\% in each case).

The results of these studies led Petrovic and his associates to state that the opinion that the final length of a mammalian mandible cannot be increased orthopedically or orthodontically beyond a genetically predetermined value is unfounded. They stated that a genetically predetermined length of the mandible could not be detected in their experiments in rats.

Although we have reported on short-term protrusive experiments in animals of various age groups, ${ }^{14-17.19}$ no studies have been reported by us or others in which a nonhuman primate wore a protrusive appliance from the mixed dentition period to adulthood. Therefore, the purpose of this study was to investigate the changes that occur in mandibular growth rate and direction in animals wearing a protrusive appliance from the juvenile age period to adulthood. We compared the rates and directions of growth in these animals longitudinally and tried to determine whether or not the final length of the mandible could be significantly altered at the end of the growth period.

\section{MATERIALS AND METHODS}

Twelve control and 11 experimental juvenile male rhesus monkeys (Macaca mulatta) were used. Since the exact ages of these animals were not known, the maturational level was based on the developmental stage of the dentition. Each animal had a complete deciduous dentition with the exception of erupted first molars and occasionally the exception of the upper central incisors. According to the tooth eruption tables of Hurme and Van Wagenen, ${ }^{20}$ these animals were 18 to 24 months 


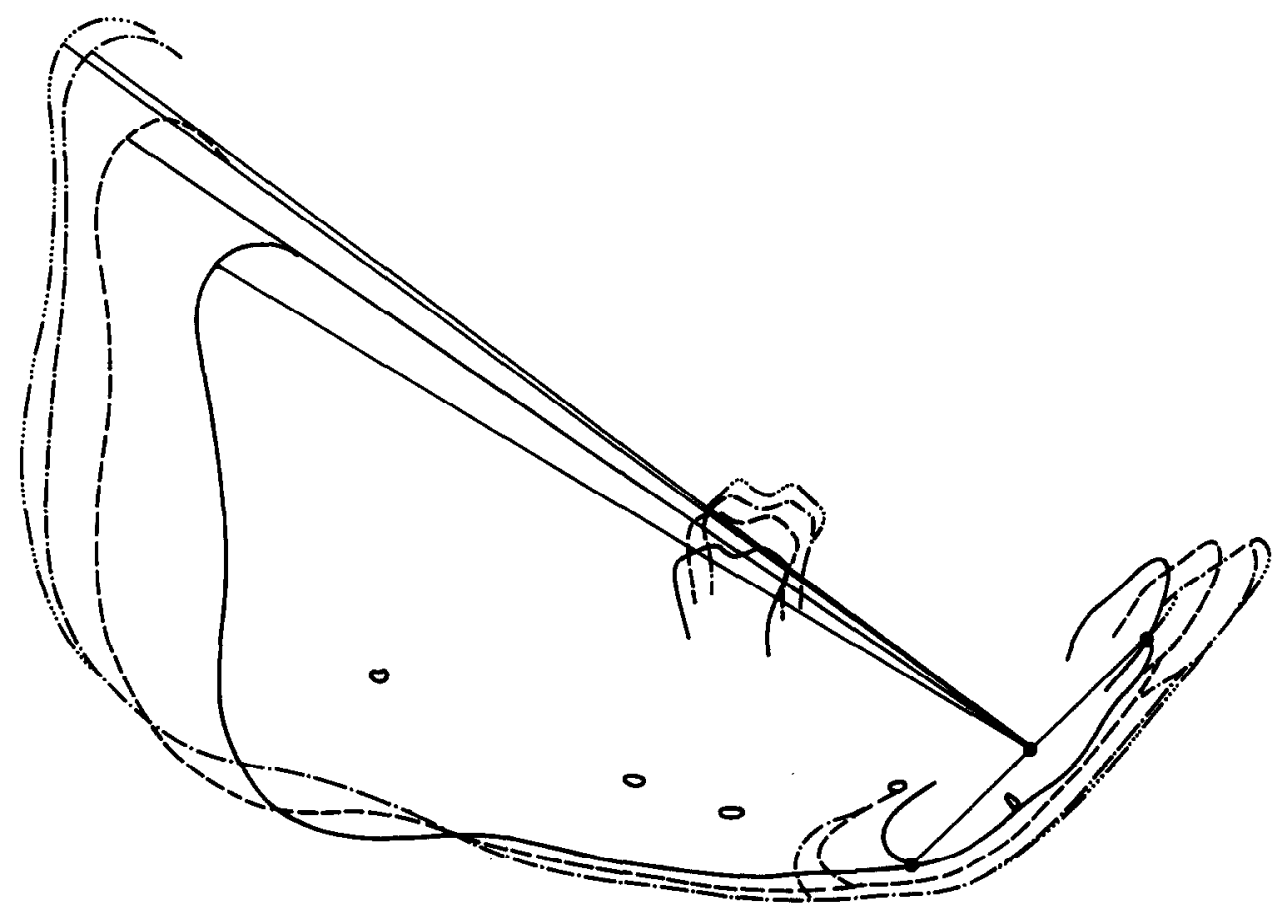

Fig. 2. Determination of mandibular length by construction of an artificial landmark in the middle of the mandibular symphysis (symphyseal point).

of age at the beginning of the experiment and corresponded to human subjects who are in the early mixed dentition period.

For all experimental procedures, the animals were sedated with ketamine hydrochloride ( 7 to $15 \mathrm{mg} / \mathrm{kg}$ intramuscularly) and rompun (xylazine) (1 to $2 \mathrm{mg} / \mathrm{kg}$ intramuscularly). From sets of impressions taken on each animal, mandibular and maxillary appliances were constructed to displace the mandible 2 to $3 \mathrm{~mm}$ inferiorly and 4 to $5 \mathrm{~mm}$ anteriorly. Before cementation the appliances were equilibrated to allow for maximal occlusal contact.

The appliances were removed at 6-month intervals and replaced with new appliances fabricated in the same manner. The new appliances provided an additional forward advancement of the bite, the exact amount depending upon the tolerance of the animal. At certain intervals during the transition of the dentition, appliance placement was impossible for 3 to 6 months due to the lack of erupted teeth.

\section{Cephalometric technique}

Serial cephalograms were taken using a cephalometric head holder specifically designed for nonhuman primates. ${ }^{21}$ The radiographs were duplicated on translite films so that the image was enlarged to three times the size of the original radiograph. ${ }^{14}$ This was done to min- imize tracing errors and to increase the accuracy of the quantification of small changes.

All animals were radiographed immediately before appliance placement, immediately after appliance placement, and at 12-week intervals throughout the study. For the purpose of this study, the initial radiographs were compared with radiographs taken at 48 weeks, 96 weeks, and 144 weeks after appliance placement. Skeletal changes were quantified by measuring superimposed tracings of the enlarged cephalograms with the initial radiograph used as the baseline for comparison. Measurements were made by calipers directly from the composite tracings. An error of the method study of this technique has been reported previously. ${ }^{14}$

Mandibular length. The overall length of the mandible was determined by two measurements.

1. CONDYLION TO INFRADENTALE. The maximum length of the mandible (Fig. 1) was determined by directly measuring from the most posterosuperior aspect of the condyle (condylion) to the junction point between the anterior outline of the lower incisor and the adjacent alveolar bone (infradentale). Both landmarks move over time in a growing animal.

2. CONDYLION TO SYMPHYSEAL POINT. To use the mandibular implants in analyzing serial growth change, an artificial landmark (symphyseal point) was con- 


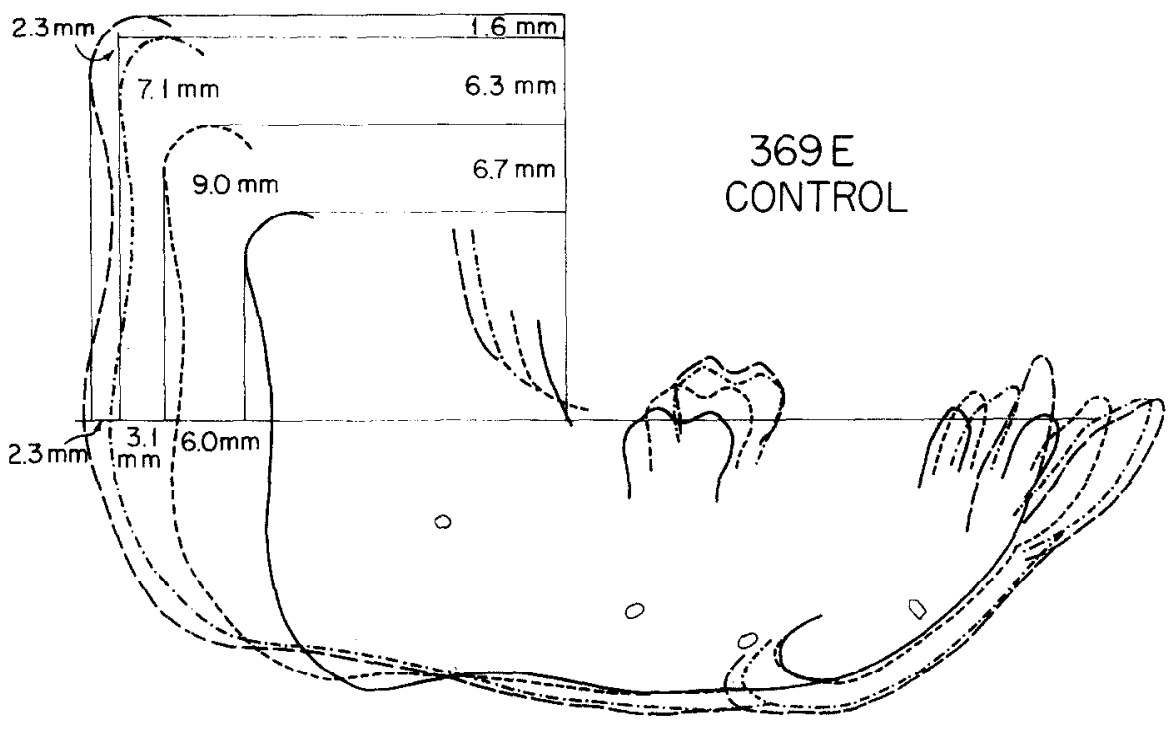

Fig. 3. Typical mandibular growth in a control animal durlng a 144-week period. Note the superiorposterior relocation of the mandibular condyle. Solid line, Start of experiment. Short dashed line, Fortyeight weeks. Dashed-dotted line, Ninety-six weeks. Long dashed line, One hundred forty-four weeks.

structed in the middle of the symphysis. The position of this landmark (Fig. 2) was determined by bisecting a line drawn between infradentale and the intersection point of the lingual outline of the mandibular symphysis with the lower border of the mandible. Composite serial tracings of the mandible of each animal were made, superimposing on the implants. Measurements of mandibular length from the unchanging position of the symphyseal point to the changing position of condylion were then made. This method of measuring eliminated the influence of changing anterior landmarks, such as infradentale.

Condylar increments. Changes in condylar position were monitored by the method used routinely in our laboratory. ${ }^{15,21,22}$ An occlusal reference line was drawn along the functional occlusal plane of the first cephalometric film (see: Figs. 3 and 4 later in the text). A vertical line was constructed perpendicular to the occlusal reference line at the point of its intersection with the anterior border of the ramus. This method provided a means of quantifying skeletal changes relative to the mandibular implants in successive cephalograms.

\section{Statistical analysis}

Student's $t$ test was used to compare the experimental and control groups at each of the four times of measurement. Since this was a longitudinal study, three tests for any given measurement could not reasonably be assumed to bc independent. Consequently, Bonferroni's correction ${ }^{23}$ was used--that is, the $P$ values for each of the tests were multiplied by 4 (the number of tests for each measurement) before assuming their significance. In other words, the levels of significance indicated in Tables 1 through 4 have been corrected in the sense that they refer to the possibility of committing a type I error on one or more of the four tests actually performed for each measurement.

\section{RESULTS \\ Comparison of pretreatment size}

One of the aims of this study was to determine the effect of the protrusive appliance on the growth of the mandible. In order to do so, it was important to establish at the beginning of the experiment that the control and experimental groups were as closely matched as possible with regard to the developmental age, sex, and size of the mandiblc. As mentioncd earlier, the animals were all of the same sex and dental developmental age. The two measures of mandibular length previously described (that is, condylion to infradentale and condylion to symphyseal point) were used to assess the pretreatment size of the mandible. As can be seen in Table I, there was less than $1 \mathrm{~mm}$ average difference in the pretreatment mandibular lengths, a difference that was not statistically significant. Thus, the mandibles of the control and experimental groups were indistinguishable in length at the beginning of the experiment.

\section{Analysis of experimental results}

To evaluate the incremental and overall changes in mandibular size and shape, tracings of serial head films were superimposed on the mandibular implants at 48 - 
Table I. Pretreatment mandibular length

\begin{tabular}{l|c|c|c|c|c|c|c|c|c}
\hline & \multicolumn{4}{|c|}{ Control $(N=12)$} & \multicolumn{4}{c|}{ Experimental $(N=11)$} & \multirow{2}{*}{ Significance } \\
\cline { 2 - 8 } & $\bar{X}$ & $S D$ & Minimum & Maximum & $\bar{X}$ & $S D$ & Minimum & Maximum & NS \\
\hline Co-inf & 61.3 & 4.4 & 55.0 & 67.7 & 61.9 & 2.4 & 57.9 & 66.7 & NS \\
Co-sym & 57.1 & 3.7 & 52.0 & 63.1 & 58.0 & 2.3 & 54.2 & 63.0 & \\
\hline
\end{tabular}

Table II. Forty-eight-week mandibular length

\begin{tabular}{|c|c|c|c|c|c|c|c|c|c|}
\hline & \multicolumn{4}{|c|}{ Control $(N=12)$} & \multicolumn{4}{|c|}{ Experimental $(N=11)$} & \multirow[b]{2}{*}{ Significance } \\
\hline & $\bar{X}$ & $S D$ & Minimum & Maximum & $\bar{X}$ & $S D$ & Minimum & Maximum & \\
\hline$\Delta$ Sup cond & 8.2 & 1.6 & 6.0 & 10.8 & 8.5 & 2.2 & 5.1 & 12.3 & NS \\
\hline$\Delta$ P.S. cond & 10.1 & $1 . \dot{5}$ & 8.0 & 13.1 & 13.1 & 2.0 & 9.8 & 16.4 & $* *$ \\
\hline$\Delta$ Post cond & 6.3 & 1.7 & 4.2 & 9.1 & 10.0 & 1.6 & 7.4 & 12.8 & $* * *$ \\
\hline$\Delta$ Co-sym & 9.0 & 1.8 & 5.5 & 12.1 & 12.8 & 1.8 & 9.6 & 15.7 & $* * *$ \\
\hline$\Delta \mathrm{Co}$-inf & 10.8 & 1.7 & 8.3 & 13.4 & 14.6 & 2.1 & 10.7 & 17.0 & $* * *$ \\
\hline Co-inf & 72.1 & 4.3 & 63.3 & 78.3 & 76.5 & 3.7 & 70.7 & 83.7 & $* *$ \\
\hline Co-sym & 66.1 & 4.4 & 59.2 & 73.2 & 70.7 & 3.5 & 66.1 & 78.7 & $* * *$ \\
\hline
\end{tabular}

$* *<0.01$.

$* * *<0.001$

Table III. Ninety-six-week mandibular length

\begin{tabular}{|c|c|c|c|c|c|c|c|c|c|}
\hline & \multicolumn{4}{|c|}{ Control $(N=12)$} & \multicolumn{4}{|c|}{ Experimental $(N=9)$} & \multirow[b]{2}{*}{ Significance } \\
\hline & $\bar{X}$ & $S D$ & Minimum & Maximum & $\bar{X}$ & $S D$ & Minimum & Maximum & \\
\hline$\Delta$ Sup cond & 6.6 & 2.0 & 2.0 & 9.9 & 5.7 & 2.7 & 1.0 & 10.4 & NS \\
\hline$\Delta \mathrm{P} . \mathrm{S}$. cond & 8.2 & 2.5 & 3.3 & 11.9 & 9.0 & 2.2 & 4.7 & 11.7 & NS \\
\hline$\Delta$ Post cond & 4.7 & 1.9 & 2.1 & 8.2 & 6.3 & 1.6 & 2.9 & 8.1 & $*$ \\
\hline$\Delta C_{0}$-sym & 8.0 & 2.3 & 3.1 & 11.1 & 8.6 & 2.0 & 4.7 & 11.2 & NS \\
\hline$\Delta$ Co-inf & 8.4 & 2.4 & 4.0 & 12.0 & 10.4 & 2.2 & 5.6 & 13.3 & $*$ \\
\hline Co-inf & 80.4 & 3.7 & 71.7 & 86.3 & 87.0 & 3.4 & 81.7 & 91.7 & $* * *$ \\
\hline Co-sym & 74.0 & 3.4 & 66.6 & 80.5 & 79.6 & 2.8 & 76.3 & 83.7 & $* * *$ \\
\hline
\end{tabular}

$*<0.05$.

$* * *<0.001$

week, 96-week and 144-week intervals according to the method previously described (Figs. 3 and 4).

Forty-eight weeks. At the end of 48 weeks, statistically significant differences in the increments of growth at the condyle could be observed. The largest percent increase was seen along the posterior aspect of the condyle. During the 48-week period, there was an increase in the posterior condylar measurement of 10.0 $\mathrm{mm}$ in the experimental group as compared with 6.3 $\mathrm{mm}$ in the control group-values that were statistically significant (Table II, Fig. 5). Similar differences in growth rate were scen at the posterosuperior aspect of the condyle in which there was a $13.1 \mathrm{~mm}$ increase in the experimental group as compared with a $10.1 \mathrm{~mm}$ increase in the controls. In contrast to the previous two measures, there was no significant increase in the amount of superior growth of the condyle. By combining the results of all three measures, it was obvious that not only the rate but also the direction of condylar growth was altered more posteriorly in the experimental animals during the first 48 weeks of the study.

Significant changes in the increases in mandibular length and in the overall length of the mandible could be observed after 48 weeks. The measurement from infradentale to condylion was $14.6 \mathrm{~mm}$ in the experimental group and $10.8 \mathrm{~mm}$ in the control group (Table II). This resulted in the mandibles of the experimental animals being approximately $4 \mathrm{~mm}$ longer than those of the controls $(76.5 \mathrm{~mm}$ versus $72.1 \mathrm{~mm}$ ).

Similar findings were observed in the measurement 


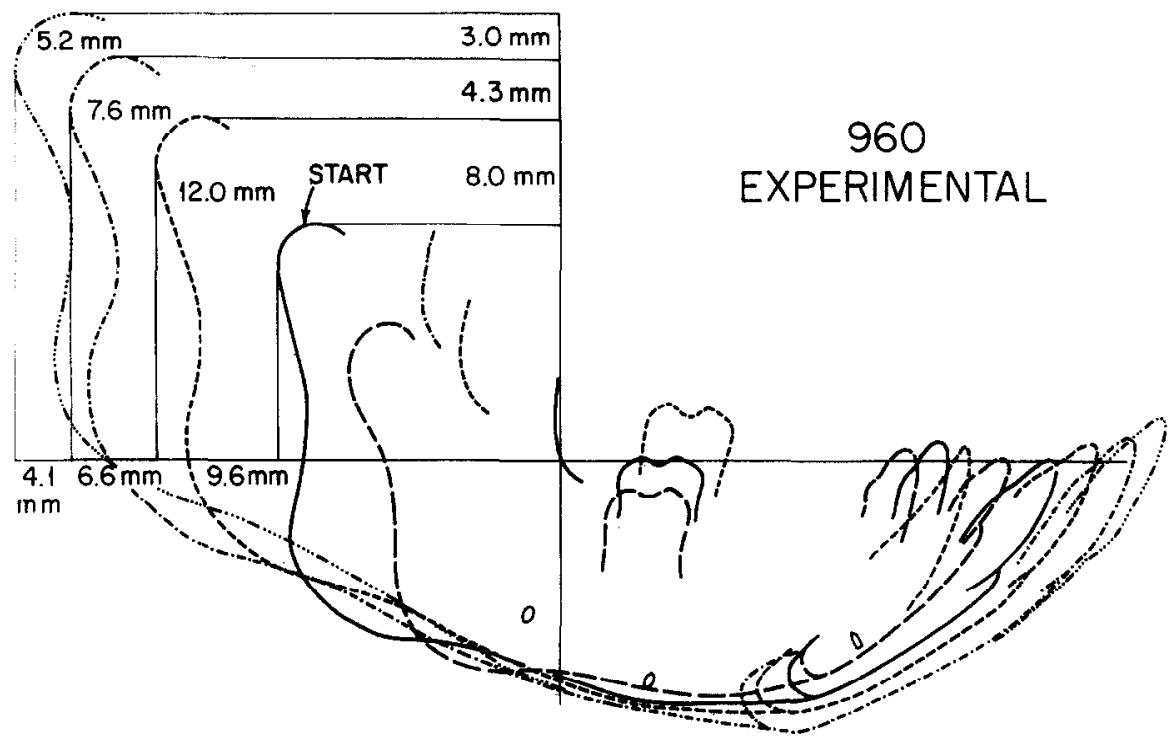

Fig. 4. Typical mandibular adaptations in an experimental animal. This animal had a 48-week control period (long dashed lines) before the start of the experiment. Solid line, Start of the experiment. Short dashed line, Forty-eight weeks. Dashed-dotted line, Ninety-six weeks. Dashed-multiple dotted line, One hundred forty-four weeks.

from the condyle to the symphysis- $70.7 \mathrm{~mm}$ in the experimental group versus $66.1 \mathrm{~mm}$ in the controls (Table II).

Ninety-six weeks. At the end of this experimental interval, almost all permanent teeth were erupted, except for the thircl molars and the upper canines, indicating that the animals were roughly equivalent in age to adolescent humans.

The overall growth rate of both the experimental and control animals was reduced from that seen during the first 48 weeks of treatment (Figs. 3 through 5). Only one measure of condylar growth increase was statistically significant-that of the posterior condyle. In the experimental group, the average value was $6.3 \mathrm{~mm}$ as compared with $4.7 \mathrm{~mm}$ in the control group (Table III, Fig. 6). There was no significant difference between the growth increments observed posterosuperiorly or superiorly in the condyle. An analysis of mandibular length increments and overall mandibular length indicated that if the measurement from infradentale to condylion was used, the experimental animals on the average experienced a $2 \mathrm{~mm}$ greater increase in mandibular length than did the controls during the interval from 48 to 96 weeks. This resulted in the overall length of the mandibles of the experimental group being $6.6 \mathrm{~mm}$ longer than those of the controls, a statistically significant difference (Table III). If the measurement from the condyle to the symphyseal point was used as an indicator of overall mandibular length, the mandibles of the experimental animals were 5.6

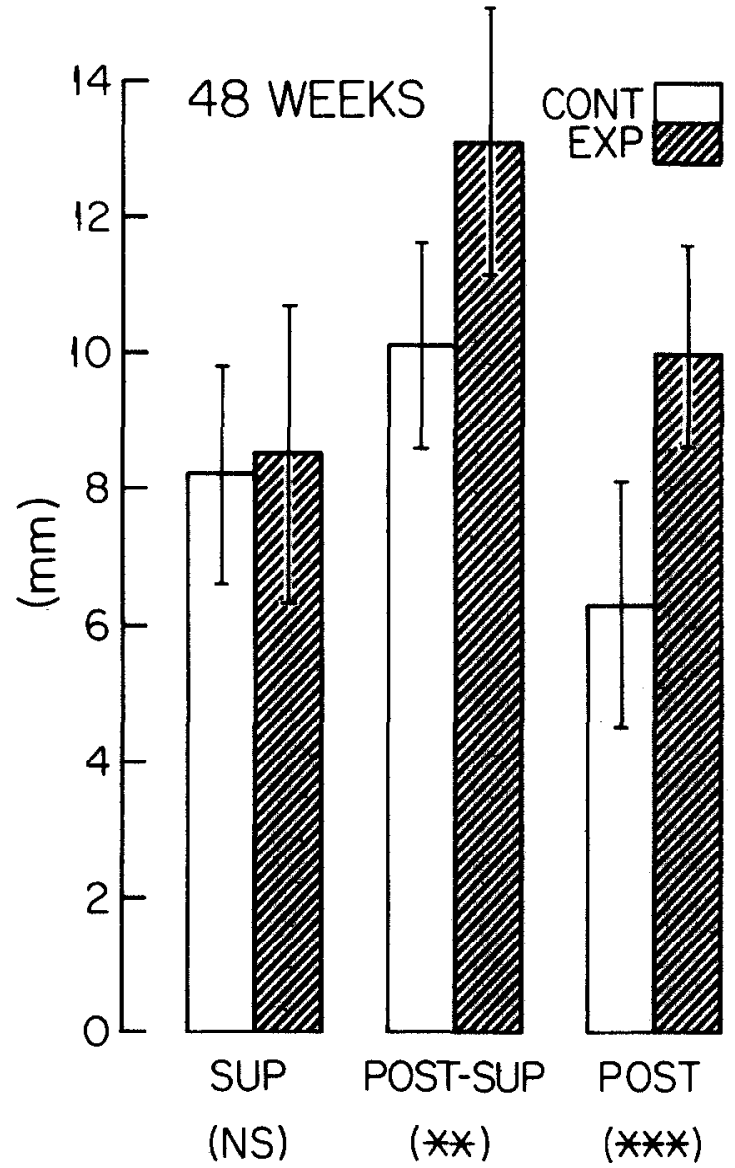

Fig. 5. Condylar growth increments during the first 48 weeks of the study. 


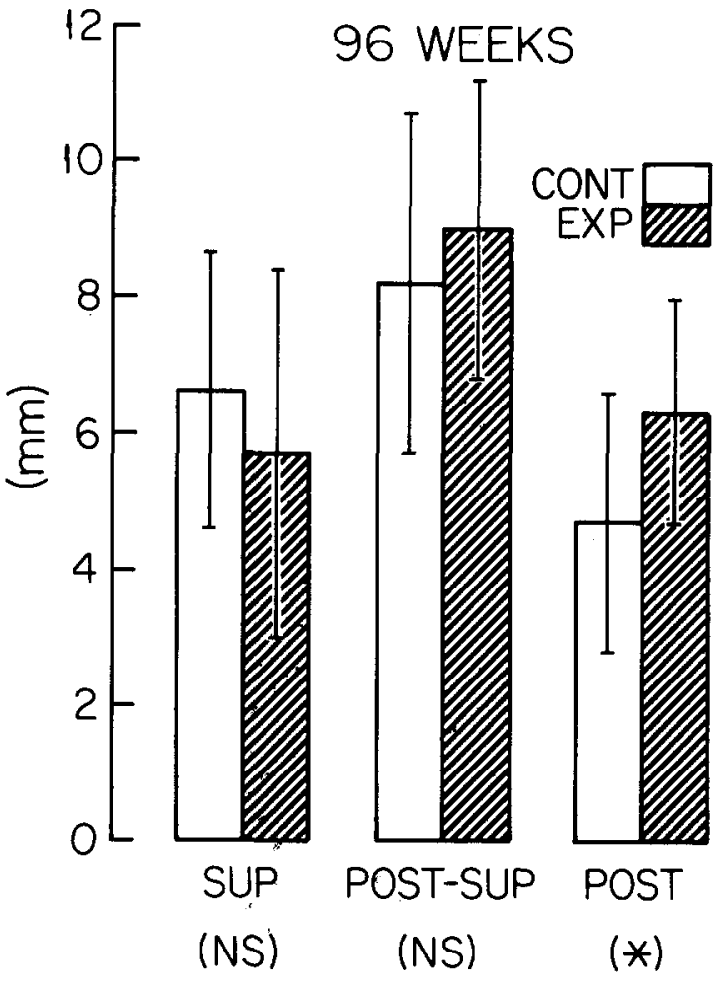

Fig. 6. Condylar growth increments from 48 to 96 weeks of the study.

mm longer than those of the controls, again a statistically significant difference.

In summary, the experimental and control animals were growing at a lesser rate than in the previous time interval. However, there were still indications that the appliance was having an effect on condylar growth and overall mandibular length.

One hundred forty-four weeks. At this time interval, the animals could be classified as adults because all permanent teeth, including third molars, had erupted.

There was no significant difference in the condylar growth increments between the experimental and control groups (Table IV, Fig. 7). In fact, the condylar growth increments in the experimental group tended to be slightly less than those of the controls, although this difference was not statistically significant.

There was also no difference in mandibular length increments in the third year of the experiments. However, at the end of the 144-week period, the mandibles of the experimental animals were still significantly longer than those of the control animals. The greatest difference was seen in the condylion-infradentale measure in which the average length of the mandible was 91.8 $\mathrm{mm}$ in the experimental group and $85.8 \mathrm{~mm}$ in the

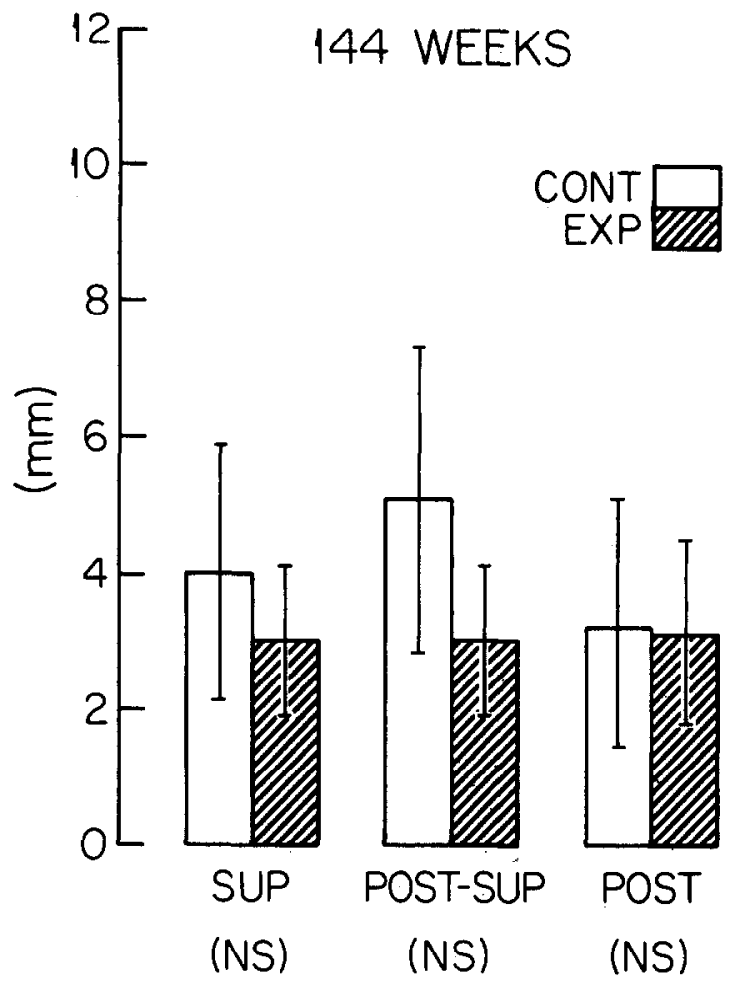

Fig. 7. Condylar growth increments from 96 to 144 weeks of the study.

controls (Table IV, Fig. 7). When the distance from the condyle to the symphyseal point was measured, the experimental mandibles were, on the average, almost $5 \mathrm{~mm}$ longer than the control mandibles.

\section{The ramus-corpus relationship}

The relationship of both the condyle and the ramus to the body of the mandible was determined by the angle of intersection of the occlusal reference line with a line drawn from the posterior border of the condyle through the most posterior point on the ramus (Figs. 8 and 9). This angle was termed the condylar-ramusocclusal (CRO) angle. ${ }^{22}$ The mandibular plane could not be used for reference because of the generalized apposition along the lower border of the mandibular corpus and the irregular remodeling of the gonial angle as the animal increased in age.

A progressive closure of the $\mathrm{CRO}$ angle occurred in the control group (Table V, Figs. 8 and 10). The average CRO angle in the control group at the start of the experiment was $96.3^{\circ}$. By the end of 144 weeks, this angle had closed to $87.5^{\circ}$.

The opposite finding was observed in the experimental animals (Figs. 9 and 10). The average initial 


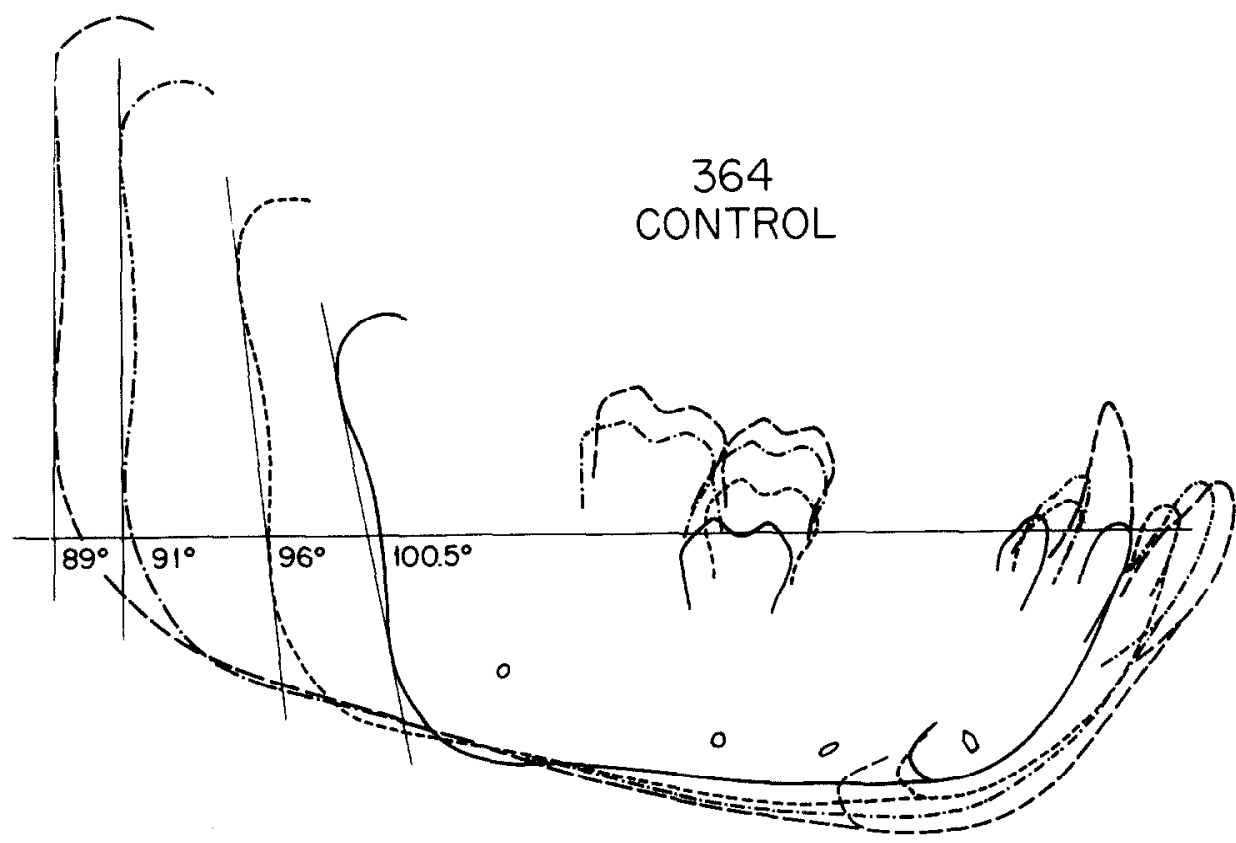

Fig. 8. Normal closure of the CRO angle in a control animal. Solid line, Start of experiments. Small dashed line, Forty-eight weeks. Dashed and dotted line, Ninety-six weeks. Long dashed line, One hundred forty-four weeks.

Table IV. One-hundred-forty-four-week mandibular length

\begin{tabular}{|c|c|c|c|c|c|c|c|c|c|}
\hline & \multicolumn{4}{|c|}{ Control $(N=12)$} & \multicolumn{4}{|c|}{ Experimental $(N=9)$} & \multirow[b]{2}{*}{ Significance } \\
\hline & $\bar{X}$ & $S D$ & Minimum & Maximum & $\bar{x}$ & $S D$ & Minimum & Maximum & \\
\hline$\Delta$ Sup cond & 4.0 & 1.9 & 1.0 & 7.6 & 3.0 & 1.1 & 1.5 & 4.6 & NS \\
\hline$\Delta P$.S. cond & 5.1 & 2.2 & 1.7 & 8.5 & 3.0 & 1.1 & 1.5 & 4.6 & NS \\
\hline$\Delta$ Post cond & 3.2 & 1.9 & 0.9 & 7.8 & 3.1 & 1.4 & 1.8 & 5.4 & NS \\
\hline$\Delta$ Co-sym & 4.6 & 1.9 & 1.6 & 7.0 & 4.0 & 1.4 & 2.2 & 6.6 & NS \\
\hline$\Delta$ Co-inf & 5.4 & 2.0 & 2.3 & 8.3 & 4.8 & 1.4 & 3.3 & 7.4 & NS \\
\hline Co-inf & 85.8 & 4.4 & 77.0 & 91.3 & 91.8 & 3.5 & 86.3 & 96.7 & $* * *$ \\
\hline Co-sym & 78.7 & 3.7 & 71.2 & 84.1 & 83.6 & 2.9 & 78.9 & 87.0 & $* * *$ \\
\hline
\end{tabular}

$* * *<0.001$.

Table V. Condyląr-ramus-occlusal angle

\begin{tabular}{|c|c|c|c|c|c|c|c|c|c|c|c|}
\hline & \multicolumn{5}{|c|}{ Control } & \multicolumn{5}{|c|}{ Experimental } & \multirow[b]{2}{*}{ Significance } \\
\hline & $N$ & $\bar{X}$ & $S D$ & Minimum & Maximum & $N$ & $\bar{X}$ & $S D$ & Minimum & Maximum & \\
\hline Initial & 12 & $96.3^{\circ}$ & $4.0^{\circ}$ & $90.0^{\circ}$ & $101.5^{\circ}$ & 11 & $95.3^{\circ}$ & $4.0^{\circ}$ & $90.0^{\circ}$ & $104.0^{\circ}$ & NS \\
\hline 48 week & 12 & $91.7^{\circ}$ & $4.7^{\circ}$ & $83.5^{\circ}$ & $100.0^{\circ}$ & 11 & $99.3^{\circ}$ & $3.1^{\circ}$ & $93.5^{\circ}$ & $104.0^{\circ}$ & $* * *$ \\
\hline 96 week & 12 & $89.2^{\circ}$ & $4.3^{\circ}$ & $81.0^{\circ}$ & $96.0^{\circ}$ & 9 & $97.4^{\circ}$ & $4.0^{\circ}$ & $89.5^{\circ}$ & $101.0^{\circ}$ & $* * *$ \\
\hline 144 week & 12 & $87.5^{\circ}$ & $3.4^{\circ}$ & $82.0^{\circ}$ & $92.5^{\circ}$ & 9 & $98.1^{\circ}$ & $5.0^{\circ}$ & $87.5^{\circ}$ & $104.0^{\circ}$ & $* * *$ \\
\hline$\Delta 48$ week & 12 & $-4.6^{\circ}$ & $3.2^{\circ}$ & $-9.5^{\circ}$ & $2.0^{\circ}$ & 11 & $4.0^{\circ}$ & $3.8^{\circ}$ & $-4.0^{\circ}$ & $9.0^{\circ}$ & $* * *$ \\
\hline$\Delta 96$ week & 12 & $-2.5^{\circ}$ & $2.7^{\circ}$ & $-5.0^{\circ}$ & $4.0^{\circ}$ & 9 & $-1.4^{\circ}$ & $2.8^{\circ}$ & $-5.0^{\circ}$ & $3.0^{\circ}$ & NS \\
\hline$\Delta 144$ week & 12 & $-1.7^{\circ}$ & $2.5^{\circ}$ & $-8.0^{\circ}$ & $0.1^{\circ}$ & 9 & $0.7^{\circ}$ & $2.6^{\circ}$ & $-4.0^{\circ}$ & $4.0^{\circ}$ & $*$ \\
\hline
\end{tabular}

$*<0.05$.

$* * *<0.001$. 


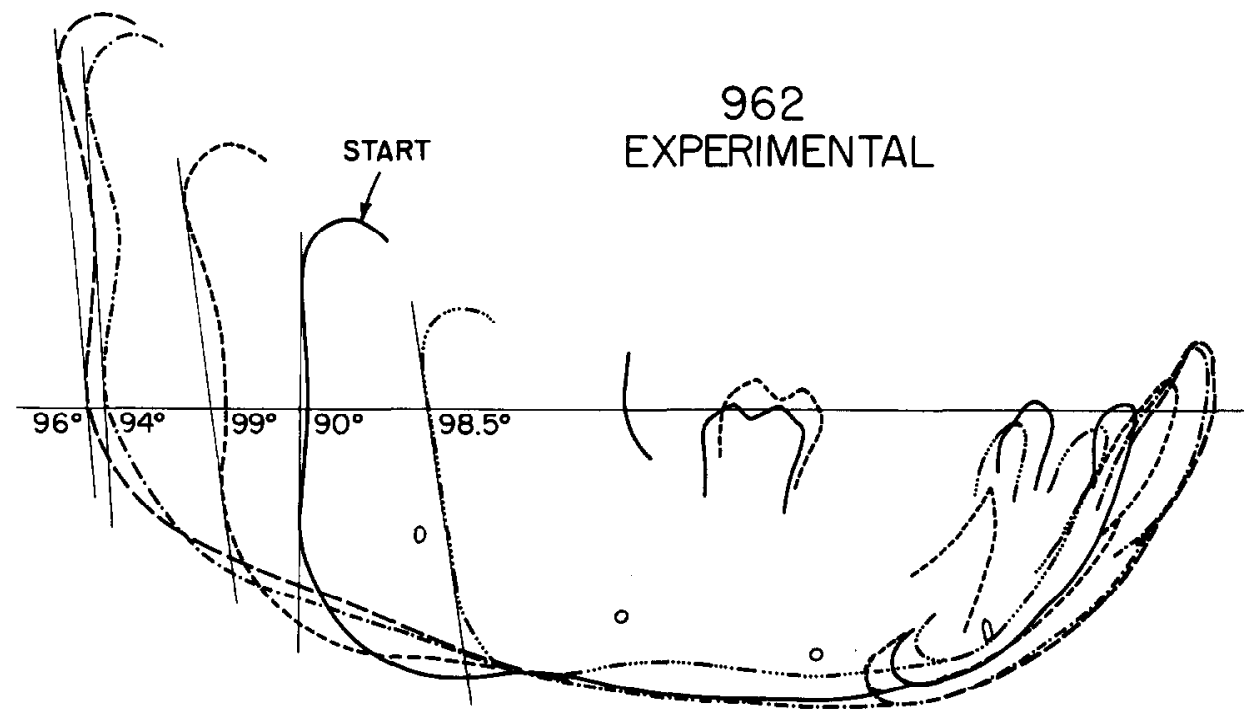

Fig. 9. The effect of treatment on the CRO angle. This animal had a 48-week control period before the onset of the experiment. Note the $8.5^{\circ}$ decrease in the CRO angle during that time. During the 144-week experimental period, there was an opening of the CRO angle, which is the opposite of what would occur during normal growth. Dashed and multiple dotted line, Control period. Solid line, Start of experiment. Small dashed line, Forty-eight weeks. Dashed and dotted line, Ninety-six weeks. Large dashed line, One hundred forty-four weeks.

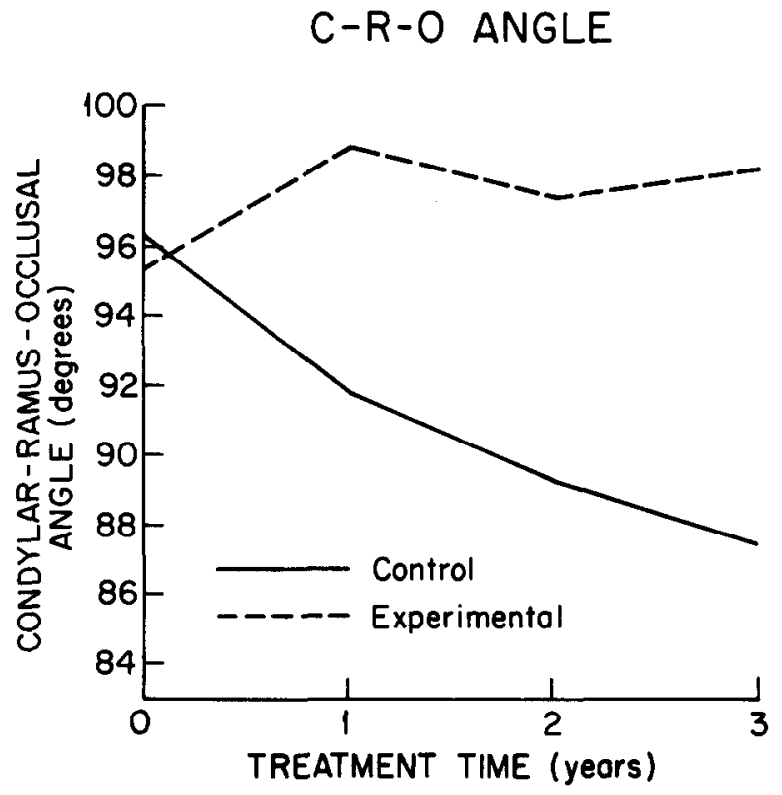

Fig. 10. Graphic representation of the change in the CRO angle during the 144-week experimental period. Note the gradual decrease in the CRO angle in the control animals, which is the opposite of what is occurring in the experimental animals.

CRO angle in this group was $95.3^{\circ}$. However, instead of steadily decreasing in value, the CRO angle increased at the end of 48 weeks to $99.3^{\circ}$. At 96 weeks it was $97.4^{\circ}$ and at 144 weeks it was $98.1^{\circ}$. Thus, the effect of the appliance was to reverse the normal pattern of closure of the CRO angle.

\section{DISCUSSION}

The results of this study indicate that in the rhesus monkey the growth of the mandible can be increased to such an extent that the adult mandible is greater in overall length than it would have been without experimental intervention. Of particular interest is the magnitude of the size change.

The most dramatic indicator of mandibular length increase was the measurement from infradentale to condylion. At the end of 144 weeks, when the animals had reached maturity, the overall mandibular length was 5 to $6 \mathrm{~mm}$ longer in the experimental animals than in the controls. This represents a $6 \%$ to $7 \%$ increase in overall mandibular length, a percentage that compares favorably with the $5 \%$ to $8 \%$ overall increase in mandibular length observed by Petrovic ${ }^{13}$ in his recent study of the postural hyperpropulsor.

Another interesting phenomenon is the relationship of maturational level to the amount of adaptation in the condyle and the overall changes in mandibular length. In a previous study in our laboratory, ${ }^{21}$ it was shown that the amount of temporomandibular joint adaptation was related to the age and maturational level of the animal. The greatest amount of condylar growth increase was observed in infant and juvenile animals, 
while no significant changes in mandibular length could be observed in the adult animals. These findings were verified on a longitudinal basis by the results of this study.

A decreasing amount of condylar growth and increases in mandibular length were observed in the control animals on a longitudinal basis. The increments of condylar growth and the changes in mandibular length during the second (adolescent) year were $75 \%$ to $82 \%$ of the values observed during the first year of the study. During the third year, the growth increments were only $43 \%$ to $51 \%$ of those observed in the control animals during the first 48 weeks of the study.

When the experimental and control animals were compared during the first year, the greatest amount of increase in condylar increments was 59\% along the posterior aspect of the condyle and a $30 \%$ increase in the posterosuperior condylar growth increment. No difference could be seen in the amount of vertical growth between the experimental and control groups.

During the second year, the only significant amount of change in condylar growth was in the posterior condyle in which the amount of growth was $34 \%$ greater in the experimental animals than the controls. There was, in fact, a $14 \%$ decrease in condylar growth along the superior aspect of the condyle relative to control averages.

\section{Clinical significance}

It is, of course, improper to make a direct comparison between a nonhuman primate study and craniofacial growth in a human population. However, it should be noted that even in the rhesus monkey, values of significance to clinicians were observed in this experimental study (that is, overall increases in the mandibular length averaged 5 to $6 \mathrm{~mm}$ ). The relative size of the mandible in the rhesus monkey can be compared with that in a human population to determine the size relationship between the two species. The average length of a human mandible, as measured from condylion to anatomic gnathion, is $120 \mathrm{~mm}$ for an adult female and $130 \mathrm{~mm}$ for an adult male. ${ }^{24}$ If the adult length of the control monkey mandible, as measured either from the condyle to infradentale $(85.8 \mathrm{~mm})$ or from the condyle to the mandibular symphyseal point $(78.7 \mathrm{~mm})$, is used for comparison (Table IV), the adult monkey mandible appears to be approximately two thirds as large as the human mandible. In this experiment an average $7 \%$ increase in mandibular length (as measured from the condyle to infradentale) was noted and one could hypothesize that a similar proportional increase in a human mandible of 8 or $9 \mathrm{~mm}$ might be possible. Because most occlusal problems in humans are in the range of $6 \mathrm{~mm}$ and the average surgical mandibular advancement is carried out in the 5- to 7-mm range, this type of potential growth augmentation is of clinical significance. However, it should be stressed that in contrast to a clinical situation, in which patient cooperation is often a factor, the protocols of the present study were performed under controlled experimental conditions. These conditions are not often duplicated in clinical practice.

\section{SUMMARY AND CONCLUSIONS}

Twenty-three male juvenile rhesus monkeys were used in an experimental study of mandibular adaptation following induced functional protrusion. At the end of the 144-week experimental period, the mandibles of the experimental monkeys were, on the average, 5 to $6 \mathrm{~mm}$ longer than those of the controls. Most of the intergroup differences were obvious after 48 weeks.

The research outlined in this article, taken together with the work of Petrovic and associates, indicates that significant adaptations can occur in the temporomandibular joint region of a growing animal. These adaptations are more observable when the animal is in the mixed dentition stage and tend to become less dramatic as the animal becomes older. The results of this study clearly show that not only is the difference in mandibular growth rate of the experimental and control animals statistically and biologically significant, it may be clinically significant as well.

\section{REFERENCES}

1. Breitner $\mathrm{C}$. Experimentelle Veräanderung der meseodistalen Beziehungen der oberen und unteren Zahnreiher. Zeitschrift fur Stomat 1930;28:343-56.

2. Breitner $\mathrm{C}$. Experimental change of the mesio-distal relations of the upper and lower dental arches. Angle Orthod 1933;3:67-76.

3. Breitner $\mathrm{C}$. Bone changes resulting from experimental orthodontic treatment. AM J ORThOD ORAL SURG 1940;26:521-7.

4. Haüpl K, Psansky R. Experimentelle Untersuchungen über Gelenktransformation bei Verwendung der Methoden der Funktionskieferorthopaedie. Deutsche Zahn-, Mund- und Kieferheilkunde 1939;6:439-48.

5. Baume JL, Derichsweiller H. Is the condylar growth center responsive to orthodontic therapy? An experimental study in $\mathrm{Ma}$ caca mulatta. Oral Surg Oral Med Oral Path 1961;14:347-62.

6. Stöckli PW, Willert HG. Tissue reactions in the temporomandibular joint resulting from anterior displacement of the mandible in the monkey. AM J ORTHOD 1971;60:142-55.

7. Vogel G, Pignanelli M. Indagini istochimiche sull'Articolazione T.M. del Macacus rhesus in corso di trattamento gnato-orthopedico. Pass Int Stomatol Prat 1958;9(suppl 4):46-50.

8. Charlier JP, Petruvic A, Stutzmann J. Effects of mandibular hyperpropulsion on the prechondroblastic zone of young rat condyle. AM J ORTHOD 1969;55:71-4.

9. Petrovic A, Oudet C, Gasson N. Effets des appareils de propulsion et de retropulsion mandibulaire sur le nombre des sarcomeres en serie du muscle pterygoidien externe et sur la crois- 
sance du cartilage condylien du jeune rat. Orthod Franc 1973;44:191-212.

10. Petrovic A, Stutzman J, Oudet C. Control process in the postnatal growth of the condylar cartilage. In: McNamara JA Jr, ed. Determinants of mandibular form and growth. Monograph 4, Craniofacial Growth Series. Ann Arbor: 1975. Center for Human Growth and Development, University of Michigan.

11. Petrovic A, Stutzman J. Further investigations into the functioning of the "comparator" of the servosystem in the control of the condylar cartilage growth rate and the lengthening of the jaw. In: McNamara JA Jr, ed. The biology of occlusal development. Monograph 7, Craniofacial Growth Series. Ann Arbor: 1977. Center for Human Growth and Development, University of Michigan.

12. Stutzman J. Particularites de la croissance postnatale de cartilages secondaires du squellette facial. Recherches in vivo et en culture organotypiquc, chez lc jcunc rat, sur les processus de commands et regulation [These de Doctorat e'Etat es-Sciences]. Strasbourg: U.L.P. Strasbourg, 1976.

13. Petrovic AG. Experimental and cybernetic approaches to the mechanism of action of functional appliances on mandibular growth. In: McNamara JA J $\mathbf{r}$, Ribbens KA, eds. Malocclusion and the periodontium. Monograph 15, Craniofacial Growth Series. Ann Arbor: 1984. Center for Human Growth and Development, University of Michigan.

14. Elgoyhen JC, Moyers RE, McNamara JA Jr, Riolo ML. Craniofacial adaptation to protrusive function in juvenile rhesus monkeys. AM J ORTHOD 1972;62:469-80.

15. McNamara JA Jr. Neuromuscular and skeletal adaptations to altered function in the orofacial region. AM J ORTHOD 1973; 64:578-606.

16. McNamara JA Jr, Carlson DS. Quantitative analysis of temporomandibular joint adaptations to protrusive function. AM J ORTHOD 1979;76:593-611.
17. McNamara JA Jr. Functional determinants of craniofacial size and shape. Eur J Orthod 1980;2:131-159.

18. Petrovic A, Stutzmann J, Gasson N. The final length of the mandible: Is it genetically determined? In: Carlson DS, ed. Craniofacial biology. Monograph 10, Craniofacial Growth Series. Ann Arbor: 1981. Center for Human Growth and Development, University of Michigan.

19. McNamara JA Jr, Hinton RJ, Hoffman DL. Histological analysis of temporomandibular joint adaptation to protrusive function in young adult thesus monkeys (Macaca mulatta). AM J ORTHOD 1982;82:288-98.

20. Hurme VO, Van Wagenen G. Basic data on the emergence of permanent teeth in the rhesus monkey. Proc Am Phil Soc 1961;105:105-40.

21. McNamara JA Jr. Neuromuscular and skeletal adaptations to altered orofacial function. Monograph 1, Craniofacial Growth Scries. Ann Arbor: 1972. Center for Human Growth and Development, University of Michigan.

22. McNamara JA Jr, Graber LW. Mandibular growth in the rhesus monkey (Macaca mulatta). Am J Phys Anthropol 1975;42: 15-24.

23. Alt FB. Bonferroni inequalities and intervals. In: Kotz S, Johnson NS, eds. Encyclopedia of statistical sciences. Vol. 1. New York: Wiley-Interscience Publication, 1982.

24. McNamara JA Jr. A method of cephalometric evaluation. AM J ORTHOD 1984;86:449-69.

Reprint requests to:

Dr. James A. McNamara

Department of Orthodontics 1027. Kellogg Dental Building

The University of Michigan

Ann Arbor, MI 48109 